\title{
A Localized Study on the Teaching Model of Flipped Classroom and Teaching Method of Micro-course
}

\author{
Yang Yanguo \\ Faculty of Fundamental Courses, Qingdao University of Technology(Linyi), Shandong, P.R.China \\ yygyoung@163.com
}

Keywords: flipped classroom, micro-course, localization, self-learning

Abstract: The paper researched the localized flipped classroom teaching model and micro-course teaching method, and created a localized teaching model-"two evaluations, three sections, four steps and nine links". The micro-course teaching method has distinctive characteristics and can significantly students' learning effect and learning ability. This study has basically achieved the expected research objectives, which proves that the teaching model and teaching method have unique advantages.

\section{1 "Two Evaluations, Three Sections, Four Steps and Nine Links"_Localized Study on Teaching Model of Flipped Classroom}

In addition to the effective self-learning of students as a basic premise, the key to achieve successful localization of the foreign flipped classroom in our school lies in whether teachers can become mentor-type teachers, lies in whether classroom teaching methods can be innovative, that is, how to design and organize learning activities, and how to guide students to carry out autonomous learning, and truly become the main body of the learning activities. To this end, my research group has made the following innovative teaching reform experiment:

1.1 The Localized Design of the Teaching Mode of Flipped Classroom. Figure 1 Teaching Method of "two evaluations, three sections, four steps and nine links"

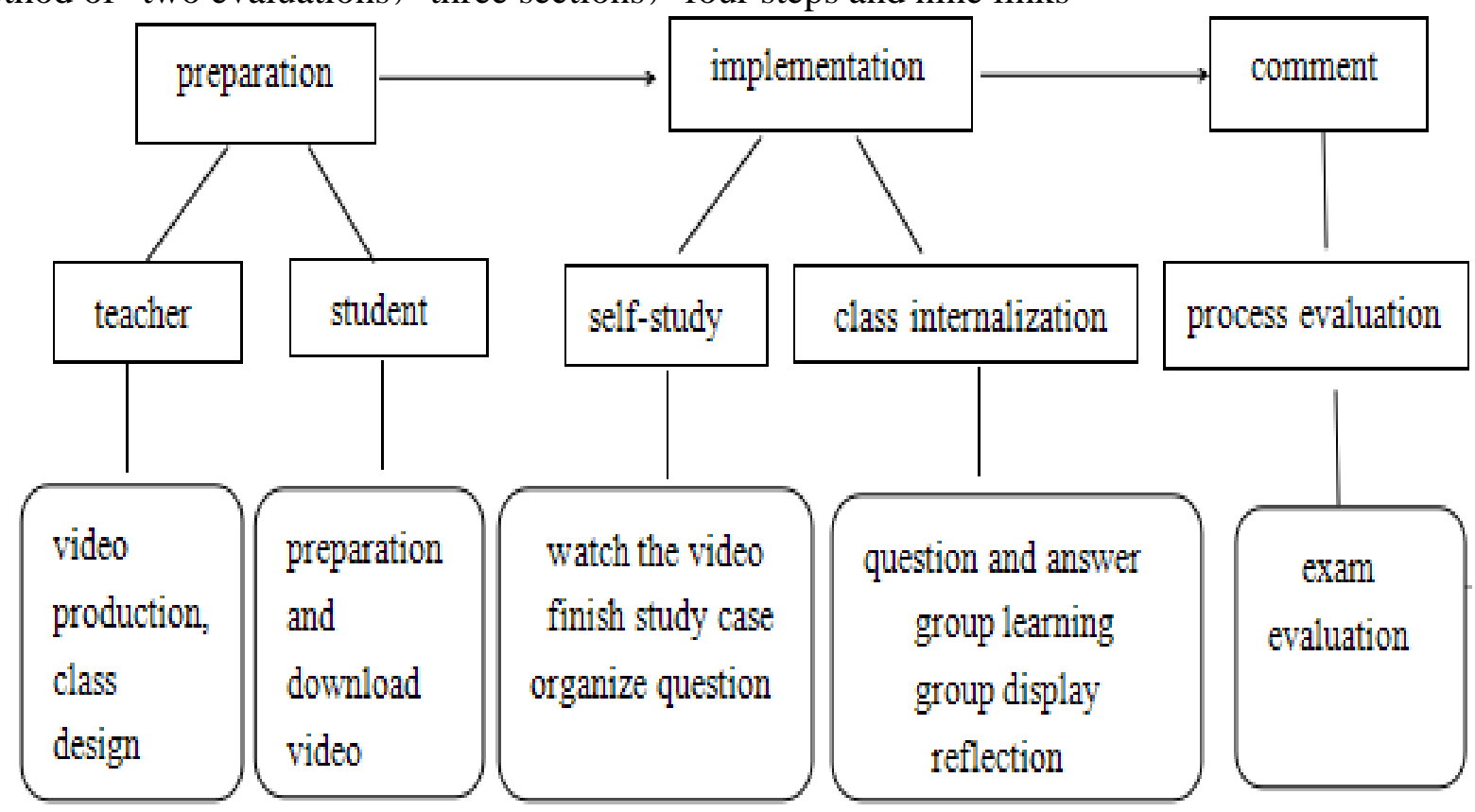

1.1.1 "Three Sections" refers to the fact that we will split the completion of the classroom into three phases, including the preparation phase of the classroom, the implementation phase and the evaluation stage.

1.1.2 "Four Steps" means that teachers should prepare these four steps in learning and teaching objectives analysis, the introduction of the case study, micro-curriculum video production and designation of classroom activities. 
1.1.3 "Nine Links" refers to the students should complete nine links in the flipped classroom learning, including pre-class video download, repeatedly watching the video, independent completion of the case study, organization of difficult questions, group learning in class, access to difficult questions, group cooperative learning, researching findings show and reflection.

1.1.4 "Two Evaluations" refers to the combination of the objective evaluation of the students with the exam evaluation and the process evaluation of group study and homework.

\subsection{The Principles of the Localization Design of the Teaching Model of Flipped Classroom}

1.2.1 Elaboration of Micro-course Video. The quality of the micro video is directly related to the final classroom effect. So, Micro-course video requires highlights, compact structure, time control within 5-10 minutes.

1.2.2 The Establishment of the Guiding Case is based on the Principle of the Student as the Main Body and the Teacher as the Leading. The design of the case study should attract students to participate in the autonomy and inquiry learning. Teachers should guide in the student's inquiry activities and be the role of mentor.

1.2.3 The Design of Classroom Activities Focuses on Testing Students' Knowledge and the Answer to Difficult Questions. Group learning should be put more emphasis on classroom activities.

\section{Research on the Innovation and Localization of the Teaching Method of Micro-course}

Through a school year teaching reform experiment, my research group believes that: teaching activity based on the unit hours is the study object of micro-course teaching method, which regards the three modules (ie, pre-class learning orders, supporting e-books and classroom teaching activities innovation), Guiding and teaching (that is, teaching students and guiding students integrate into one) as the basic model.

2.1 Research on the Basic Structure of Micro-course Teaching Method. My research group has found that the basic structure of micro-curriculum teaching method is as follows:

Figure 2 The basic structure of the micro-course teaching method

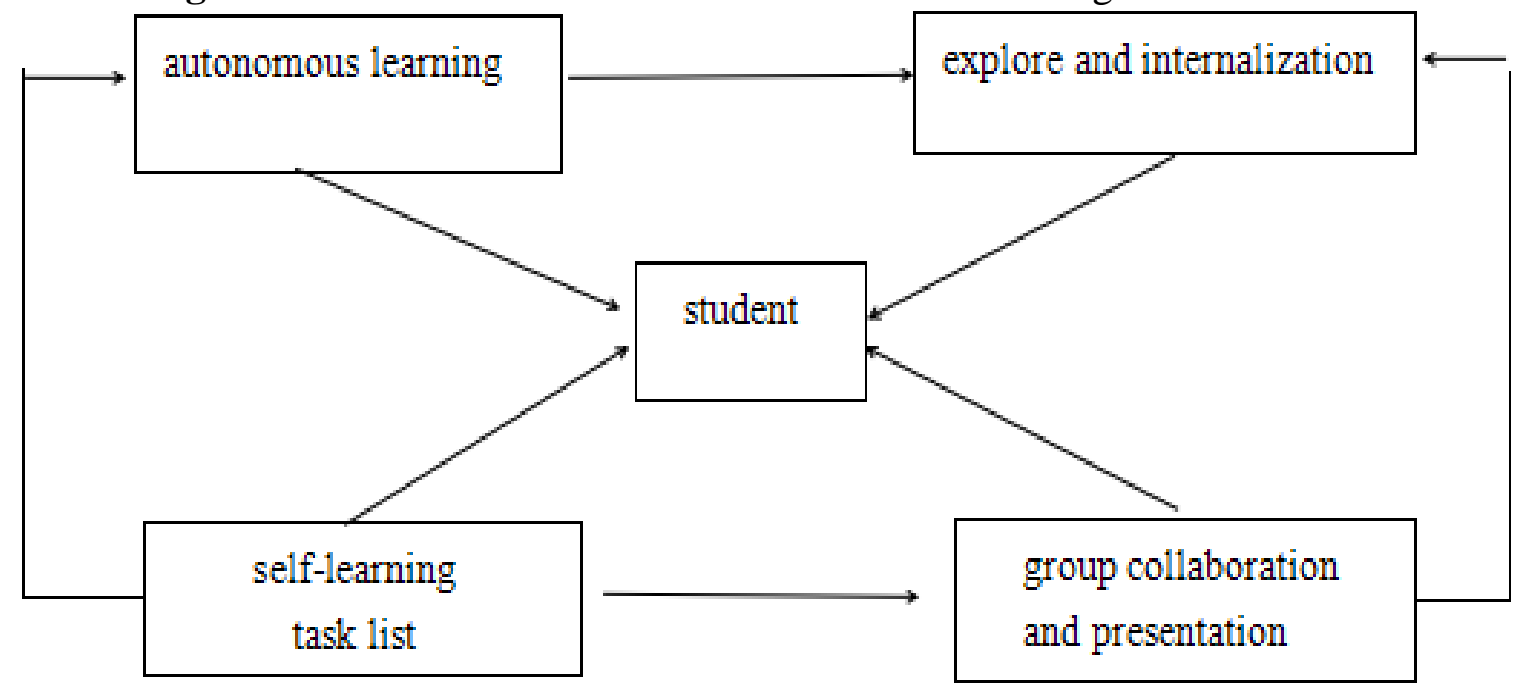

As is shown in Figure 2, in the self-learning stage of pre-class, students should learn the micro-class content prepared by teachers according to their own needs and learning tasks; in the class explore and internalization stage, teachers should explain students' puzzles and difficult problems, and use of the test, advanced assignments, group collaboration seminars, the results show and other links to guide and develop students' innovative ability and thinking ability through independent learning and team cooperation. 


\subsection{Research on the Basic Model of Micro-course Teaching Method}

Figure 3 The basic model of micro-course teaching method

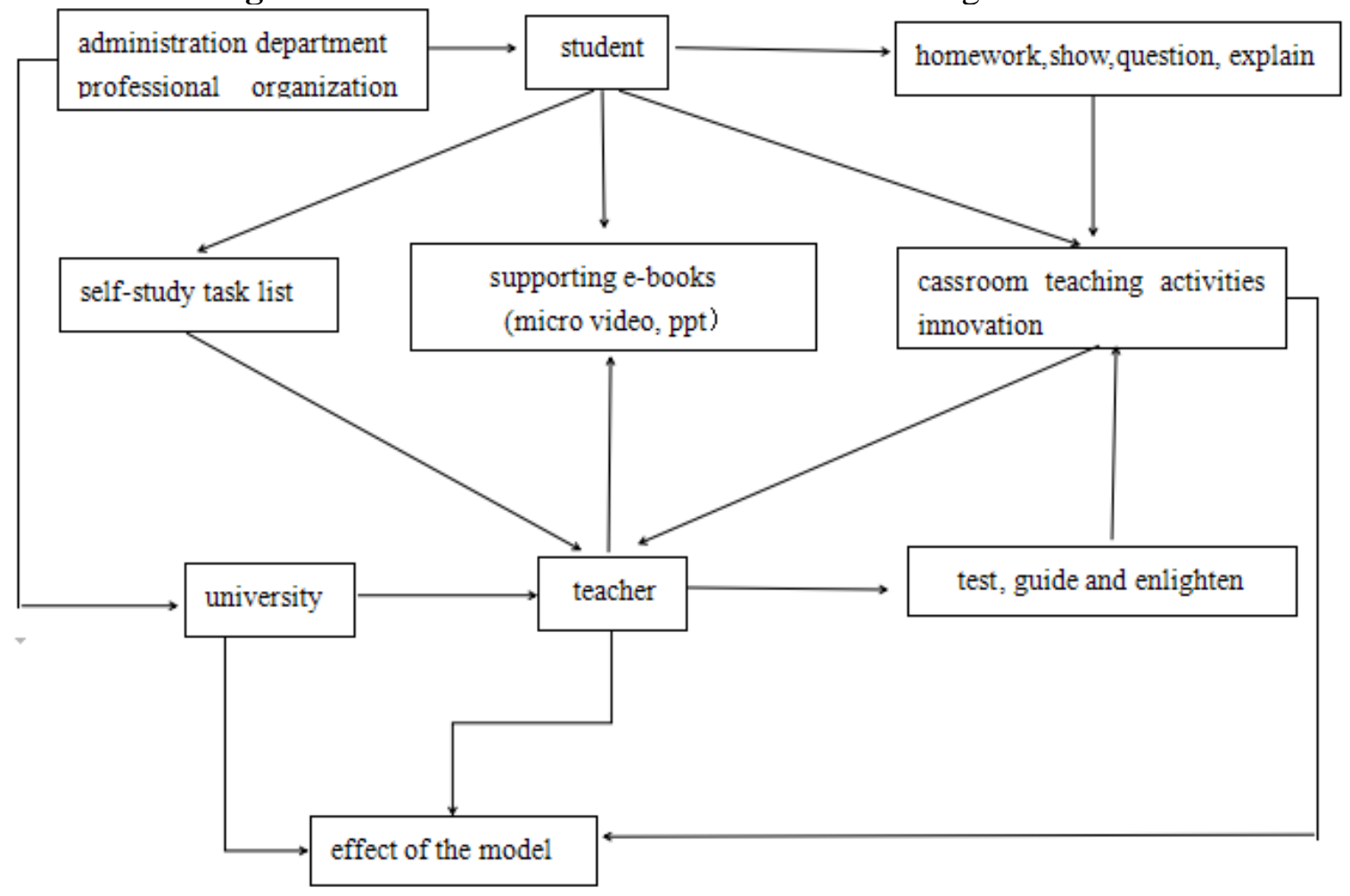

The core content of the design and development of the micro course is the design of the self-learning task sheet and the production of micro-course. Self-learning task is a program designed by teachers to guide students to study by themselves. The micro-course is to assist students to complete supporting learning content. The implementation of the micro-course mainly includes the students' autonomous learning stage in the dormitory or classroom and the internalization stage in classroom.

\section{Conclusion}

After a school year of reform experiment in the flipped classroom teaching model and micro-course teaching method, data analysis and survey results show that: the teaching model and teaching methods can fully mobilize the enthusiasm and classroom participation among students, significantly improve the students' ability to self-learning and group cooperative learning spirit.

Practice has proved that the teaching model and teaching method can improve the learning effect and promote the learning ability, which confirm the teaching model and teaching methods have unique advantages. The evaluation and popularization of micro-course is of great significance to the long-term development of micro-course teaching method, and it is necessary to study further in the future for my research group.

\section{References}

[1] Her Kehang. An Insight into the Future Development of Flipped Classroom in China from the Essence of It [J]. Electronic Education Research, 2014 (7)

[2] Jinling. Constructing "Micro-course Teaching Method" with Chinese Characteristics [J]. China Information Technology Education, 2013 (12)

[3] Jinling. Analysis on Micro-class from the perspective of Micro-course Teaching Method [J].

China Information Technology Education, 2014 (9) 
[4] Wu Zhizi. Ten years of Curriculum Reform: from the Classroom to Flipped Classroom [J]. Shanghai Education and Research, 2014 (8)

[5] Li Jiahou. Reconstruction of Teaching and Learning from the Perspective of Micro-curriculum Teaching Method [J]. Primary and Secondary Education in Information Technology, 2014 (9) [6] Zhang Xiaojun, Li Yaqin, Wang Haoyu, etc. Cognitive Load Theory from the Perspective of Micro-curriculum Multimedia Courseware Design [J]. Modern Educational Technology, 2014 (2) 